\title{
Is there really an asymmetry in the acquisition of the focus-to-accentuation mapping?
}

\author{
Aoju Chen * \\ Max Planck Institute for Psycholinguistics, P.O. Box 310, 6500 AH Nijmegen, The Netherlands
}

\section{A R T I C L E I N F O}

\section{Article history:}

Received 1 July 2009

Received in revised form 11 February 2010

Accepted 12 February 2010

Available online 13 April 2010

\section{Keywords:}

Accentuation

Focus

Asymmetry

Production

Comprehension

\begin{abstract}
A B S T R A C T
This article aims to clarify misunderstandings over the relation between production and comprehension in the acquisition of the focus-to-accentuation mapping and shed new light on this issue on the basis of experimental data obtained from Dutch-speaking children. The reanalysis of recent production data on children's and adult's intonational marking of focus reveals that 4- to 5-year-olds can use accentuation to mark noncontrastive narrow focus in question-answer dialogues, although they accent the focal noun slightly less frequently than adults in both sentence-initial and sentence-final positions and tend to accent the noun in sentence-final position to seek confirmation. Regarding comprehension, the processing of accentuation as a cue to non-contrastive narrow focus was examined in question-answer dialogues by means of the RT technique. It was found that 4- to 5-year-olds can process the mapping of non-contrastive narrow focus to accentuation although they need longer processing time than adults. Based on these results, it is argued that children's comprehension is similar to their production at the age of 4 or 5 , contra the earlier claim that production precedes comprehension in the acquisition of the focus-to-accentuation mapping. In both production and comprehension, children exhibit similar patterns to adults but are not yet fully adult-like. However, the difference between adults and children is mainly of a gradient nature.
\end{abstract}

(c) 2010 Elsevier B.V. All rights reserved.

\section{Introduction}

It is widely acknowledged that children's production precedes their comprehension in the acquisition of intonation (e.g. Cruttenden, 1985; Cutler and Swinney, 1987; Müller et al., 2006; Hendriks, 2005). Generally, children can produce adult-like phrase- and sentence-level intonation and use some of the intonational properties communicatively at the age of 2 or 3. However, they do not yet process intonational information in language comprehension as efficiently as adults do at the age of 5 or 6 and fail to interpret certain uses of intonation even at the age of 9 or 10 (e.g. Cruttenden, 1985; Cutler and Swinney, 1987). One particular aspect of sentence-level intonation well known in this context concerns the mapping between accentuation and focus in West Germanic languages. Focus is commonly defined as new information either about a situation in general or about a referent that has already been introduced into the discourse; it is comparable to the notion of 'comment' (Lambrecht, 1994; Vallduví and Engdahl, 1996). In West Germanic languages, focus is typically realised by assigning an accent to the focal (lexical) word (known as narrow focus, e.g. 'dragon' in (1)) or to one of the accentable words in the focal constituent (known as broad focus) (Ladd, 1980). Focus becomes contrastive if it forms an explicit contrast with a stated

\footnotetext{
* Tel.: +3124 3521458; fax: +31243521213.

E-mail address: aoju.chen@mpi.nl.
} 
alternative in the discourse, e.g. 'butterfly' in (2), which forms a contrast with 'dragon'. The contrast can be a rejection of information provided in the preceding discourse, also known as corrective focus, e.g. 'boat' in (3), which is a rejection of Person B's answer to Person A's question (Chafe, 1974; Gussenhoven, 2006). Contrastive focus usually has a narrow scope and is realised with more emphatic accentuation than non-contrastive focus, everything else being equal (e.g. Baumann et al., 2007; Hanssen et al., 2008). In the literature on intonational development, the accentuation in contrastive focus is sometimes referred to as 'contrastive stress' or 'emphatic stress' (hereafter 'emphatic accentuation'). The alleged asymmetry in the acquisition of the focus-to-accentuation mapping is that children acquiring a West Germanic language can correctly use accentuation to mark narrow focus at the age of 2 or 3 and yet they are poor at interpreting accentuation used as a cue to focus and exploring the association of accentuation with focus in language comprehension at the age of 4 or 5 (Cruttenden, 1985; Cutler and Swinney, 1987; Hendriks, 2005; Müller et al., 2006; Szendröi, 2004). Accounts of this asymmetry have been put forward from various theoretical perspectives in the past decades (see Cutler and Swinney, 1987 for an intonationuniversal based account; Reinhart, 1999; Szendröi, 2004, for an account based on an interface theory of focus; Hendriks, 2005 for an Optimality Theory-based account).

Person A: A boy was in the room a while ago. The boy drew something on the door. What did the boy draw? Person B: The boy drew a dragon.

Person A: Two kids were in the room a while ago. The kids drew something on the door. The girl drew a butterfly. What did the boy draw?

Person B: The boy drew a dragon.

Person A: A boy was in the room a while ago. The boy drew something on the door. What did the boy draw? Person B: The boy drew a dragon.

Person C: No, the boy drew a boat.

There are however serious problems with both the claim on children's early mastery of accentuation as a marker of narrow focus in production and the claim on their inability to interpret and process the focus-to-accentuation mapping. On the one hand, the relevant production studies only show that children can use accentuation to mark contrastive narrow focus by the age of 3 in syntactically simple sentences, in which the focused constituent is easily identifiable (more on this in section 2.1). There is no conclusive evidence on early mastery of accentuation as a marker of non-contrastive narrow focus. On the other hand, the comprehension studies cited in the literature show that children fail to process or interpret uses of accentuation when the focus-to-accentuation mapping is not transparent in the speech material, or is not the only information to be processed, or may not be essential to the experimental task (more on this in section 2.2). It is still an open question as to whether children can process or interpret the focus-to-accentuation mapping in the same discourse contexts in which they can use accentuation to mark focus.

Following a review of previous production and comprehension studies frequently cited in discussions on the alleged asymmetry (section 2), I present a reanalysis of two recent production studies to address the issue of 4- to 5-year-olds' marking of non-contrastive narrow focus compared to adults (section 3.1), and report a comprehension study on 4- to 5year-olds' processing of the mapping between non-contrastive narrow focus and accentuation (section 3.2 ). In the light of the current results, I argue that children's comprehension and production abilities are similar at the age of 4 or 5 (section 4 ). They exhibit similar patterns in both production and comprehension to adults but are not yet fully adult-like. However, the difference between adults and children is mainly of a gradient nature.

\section{Past work}

\subsection{Production}

Past work on the production of the focus-to-accentuation mapping is concerned mainly with the use of emphatic accentuation in marking contrastive narrow focus. More specifically, earlier case studies reported that some Englishspeaking children began to use emphatic accentuation to introduce contrastive information at about age 2 (Weir, 1962 ; Brown, 1973). Later experimental studies showed that English- and German-speaking children could use emphatic accentuation to mark contrastive narrow focus in different positions in SV, SVO and SVindirectOdirectO sentences at the age of 3-5 years and that there was an increase in the use of empathic accentuation in older children (for corrective contrastive focus see Hornby and Hass, 1970; MacWhinney and Bates, 1978; Baltaxe, 1984; Wells et al., 2004; for non-corrective contrastive focus see Müller et al., 2006). In these studies, children were asked to correct the experimenter's description of pictures (e.g. The girl is riding a bike-in the picture, the girl is riding a horse), or answer the experimenter's Yes/No questions about pictures (e.g. Is the girl riding a bike?), or repeat the answers to WH-questions about pictures provided by a puppet (e.g. Eva and Peter want to bake something for their mother. Eva will bake a cake. What will Peter bake?). Common to all 
these tasks is that what should be contrasted in the child's response was fairly easy to determine in the question/statementanswer/response dialogues.

The evidence cited in the literature in support of children's ability to use accentuation to express non-contrastive narrow focus comes from one study only. Wiemann (1976) observed in recordings made during natural play sessions with five 2-year-old English-speaking children that accent placement in the two-word stage was governed by the semantic relation between the two words. For example, in Verb-Locative utterances (e.g. play museum), the accent was almost always assigned to the locative (e.g. museum). However the word that would not be accented according to the semantic relation between words got accented if it carried new information or was in focus. For example, a child accented firetruck in firetruck street when answering his mother's question what is in the street. Wieman interpreted this result as evidence for 2-year-olds' ability to assign accents to mark non-contrastive narrow focus. However, her finding was based on 14 sentences in her corpora only. Wells and Local (1993) justifiably questioned the generalisability of Wiemann's finding and suggested that there could be substantial variability among young children in accent placement. Recent corpus-based studies on the intonation of two-word utterances produced by German and Dutch 2-year-olds showed that the utterances were largely produced with both words accented regardless of the semantic relations expressed and the information states (new vs. given) of the words (Behrens and Gut, 2005; Chen and Fikkert, 2007a). This finding implies that Wiemann's conclusion is not generalisable to 2-year-olds across board. As regards 3-year-olds, Chen and Fikkert (2007b) found that Dutch 3-year-olds incorrectly accented both words in Adjective-Noun utterances with only the adjective in focus.

As 2- to 3-year-olds can accent words, the failure to accent only the focal word may be due to their inability to establish what is new or focal and what is given in the discourse. There is however substantial evidence indicating that this is unlikely. Specifically, children acquiring different languages can use syntactic operations and morphological means to mark topic (i.e. a referent that has been introduced into the discourse and about which new information is provided) at a young age (e.g. Hickmann and Roland, 1990; Chien and Wexler, 1991; De Cat, 2008). Moreover, corpus-based as well as experimental studies on argument realisation in child speech have shown that children can vary lexical expressions in an adult-like way to encode information states of discourse referents at the age of 2 or 3. Like adults, they use highly informative lexical expressions (e.g. full NPs) to express referents that are new, contrastive, potentially ambiguous in the discourse, or not yet the focus of attention, but use reduced forms (e.g. pronouns) or even zero anaphora to express referents that are given, noncontrastive, unambiguous in the discourse, or the focus of attention (see Allen et al., 2008 for an overview). These findings clearly indicate that children under the age of 4 are capable of taking their interlocutor's knowledge state into account and establishing successfully what is new and what is given to their interlocutor. Two- to three-year-olds' failure to use accentuation to mark non-contrastive narrow focus therefore suggests non-mastery of the focus-to-accentuation mapping.

There is thus an asymmetry in the acquisition of the focus-to-accentuation mapping regarding different types of focus. In sentences with non-contrastive narrow focus, the focal constitute supplies information from an unlimited set of possibilities (Chafe, 1976). In sentences with contrastive narrow focus, the focal constitute is contrasted with an already stated alternative or an alternative from a closed set (Halliday, 1967; Chafe, 1976; Rooth, 1992). The availability of a limited number of possibilities in the case of contrastive narrow focus may make it easier for children to recognise the salience of the focal constituent and use accentuation to highlight it accordingly.

Note that the ability to use accentuation to mark contrastive narrow focus does not mean that children actually do this all the time. For example, Hornby and Hass (1970) observed a more frequent use of emphatic accentuation to mark subject contrast than verb- and object-contrast. Furthermore, children may or may not use accentuation to the same extent as adults do. In the studies reviewed above, data on adults' use of emphatic accentuation was not always available for comparison and when it was available, it was not included in the statistical analysis. So there is no way to know whether children are also adult-like in terms of the degree to which they use accentuation to realise contrastive narrow focus.

\subsection{Comprehension}

The comprehension studies that are supposed to provide evidence for children's inability to process the focus-toaccentuation mapping have examined children's ability regarding various uses of accentuation, including pronominal disambiguation in coordinate sentences, marking focus in sentences with the focus particle 'only', creating acceptable intonation in a sentence, directing attention to certain words in narratives, and distinguishing focus from topic in SVO sentences. These uses of accentuation may all have bearing on accentuation as a cue to focus, but the focus-to-accentuation mapping is not transparent in the speech material, or is not the only information to be processed, or may not be essential to the experimental task, as will become clear in the following paragraphs. Consequently, children's failure in the comprehension tasks in earlier studies does not necessarily suggest their inability to process the focus-to-accentuation mapping, which they can already produce by age 3. In what follows, I will summarise the main findings regarding each of the uses of accentuation and discuss the alternative interpretations of the findings. It is beyond the scope of the present study to provide empirical evidence for the alternative interpretations. The goal of the review is to highlight the issues that can severely undermine the methodological soundness of deriving conclusions on children's (in)ability to process the focus-toaccentuation mapping from these studies.

Regarding pronominal disambiguation, Solan (1980) found that 5-year-olds failed to understand the interaction between emphatic accentuation and pronouns when acting out with toys sentences like The camel hit the lion and then HE hit the 
elephant. McDaniel and Maxfield (1992) reported similar findings. The authors of both studies concluded that children were unable to interpret emphatic accentuation in an adult-like way even at the age of 5 . This would seem to be a rather strong conclusion considering that correct interpretation of the accented pronoun in such sentences requires some logical thinking in addition to knowledge of accentuation as a cue to contrast. A possible process to arrive at the right interpretation of $H E$ in the 'camel' sentence is as follows: The listener first assumes a contrast between the camel and $H E$ given the parallel nature of the two clauses connected by then. Then the listener must realise that $H E$ cannot be the camel as there is no point of contrasting the camel with himself. This leaves only one option: HE must refer to the lion. It is possible that children misinterpreted the accented pronouns not because of their inability to process the accentuation-to-contrast mapping but because of the additional logical thinking required. Notably, there is no evidence suggesting that children can use accentuation to disambiguate pronominal references in production.

Studies on children's interpretation of focus in sentences with 'only’ are abundant (e.g. Crain et al., 1994; Bergsma, 2002; Drodz and van Loosbroek, 1998; Gualmini et al., 2002; Paterson et al., 2006; Szendröi, 2004). In these studies, the sentences typically had the structure of S + only + V + Direct-Object + preposition + Indirect-Object (e.g. Barney only sold a cake to Snow White). An accent was placed either on the indirect object or on the direct object. It was found that children aged 5 appeared to resort to a default reading, i.e. the indirect-object focus reading, regardless of where the accent was and whether the accent was emphatic or not. They interpreted the direct-object spoken with emphatic accentuation as the focus only if the contextual information clearly disfavoured the indirect-object focus reading. These results led to the conclusion that 5-yearolds could not arrive at the right interpretation of focus on the basis of accentuation information. Various authors have argued that correct interpretation of focus in sentences with 'only' requires knowledge of the semantics of the focal particle and focus projection in addition to knowledge of the focus-to-accentuation mapping, and that children's failure in interpreting focus in such sentences is therefore not necessarily due to their lack of knowledge of the focus-to-accentuation mapping (Gualmini et al., 2002; Szendröi, 2004; Paterson et al., 2006). Similar to the use of accentuation in pronominal disambiguation, there is no known evidence showing that children can use accentuation correctly to mark focus in syntactically comparable sentences with 'only' at the age of 5 .

Regarding children's responses to sentences with abnormal intonation (e.g. sentences without accent or with inappropriately placed accent), Lahey (1974) noted that 4- and 5-year-olds were not significantly worse at acting out coordinate sentences and sentences with relative clauses when the sentences were spoken with a monotonous intonation pattern than when they were spoken with proper intonation. Bates (1976) observed that children's imitation of sentences was not disrupted by pragmatically inappropriate accent placement but by marked word order. Both authors interpreted these results as evidence for children's failure to process the focus-to-accentuation mapping. However, an alternative and probably more plausible interpretation of the results is that inappropriate accent placement or absence of accentuation does not make language comprehension or imitation impossible. Indeed, it has been shown that 4- and 5-year-olds had no difficulty in reconstructing sentences with acceptable intonation from the prosodically and rhythmically distorted renditions of these sentences (Müller et al., 2006; Chen, accepted for publication). Furthermore, it is quite possible that negative influence of abnormal intonation on the rapid process of language comprehension is too subtle to be captured by off-line tasks like acting-out and imitation.

In respect of children's use of focus and accentuation information in word recognition, Cutler and Swinney found (1) that 3- and 4-year-olds did not recognise words faster when the context suggested that the words were in focus than when the context did not, and (2) that some 4- and 5-year-olds did not recognise words faster when the prosody of the preceding segments suggested that these words were accented than when the prosody of the preceding segments did not. Cutler and Swinney concluded that children under the age of 5 or 6 could not exploit focus and accentuation information as efficiently as adults do in online language comprehension. Note that focus and accentuation were manipulated separately (i.e. the words were accented regardless of focus condition in the 'focus stories'; the words were not obviously in focus or out of focus in the 'accent stories') in Cutler and Swinney's study. Their findings thus have very limited implications for children's ability in processing the focus-to-accentuation mapping.

Among the studies addressing comprehension of accentuation, the focus-to-accentuation mapping examined in Hornby's (1971) comprehension experiment was probably most comparable to what children could produce by age 3 . In the same study, Hornby also investigated the use of emphatic accentuation in marking corrective focus in production by the same children taking part in the comprehension experiment. The results are, however, open to different interpretations. In the comprehension experiment, children at three age levels $(6,8,10$ years $)$ were asked to select the picture that they believed the experimenter was talking about from two pictures a time. Neither picture fitted perfectly with the experimenter's description, which was given in different types of sentences (e.g. sentences with cleft-structure, SVO sentences with one word spoken with emphatic accentuation, etc.). One of the pictures contained the topic and the other contained the focus or comment of the sentence. Topic and focus were defined differently in different sentence types. Relevant to us here is children's responses in the six sentences employing emphatic accentuation. In these sentences, either the subject or the verb was spoken with emphatic accentuation. It was assumed that the unaccented part was the topic and the accented element was the focus. Hornby found that on average 6-, 8- and 10-year-olds interpreted 3.45 times, 3.25 times, and 4 times respectively the unaccented subject as the topic and selected the picture containing the same subject, as in the experimenter's description. In the subsequent production experiment, the same children were asked to correct the experimenter's descriptions of a set of 30 pictures. It was found that on average 6-, 8- and 10-year-olds used emphatic accentuation to realise the correction 16.6 times, 13.25 times and 12 times respectively. Hornby concluded that children 
from all the three age groups interpreted the subject as the topic of the sentence when unaccented but as the focus of the sentence when accented above the chance level, and that they all could use emphatic accentuation to realise corrective focus, though the use of emphatic accentuation decreased in older children. Cutler and Swinney (1987) suggested a more stringent interpretation of the results, given the fact that 6-and 8-year-olds interpreted an unaccented subject as the topic in about half of the time. They claimed that 6 -year-olds performed at chance level in comprehension but used accentuation cues above chance in production, and considered this as a strong piece of evidence for an asymmetry in the acquisition of the focus-to-accentuation mapping. However, the relatively poor performance in comprehension may be a task-induced effect. More specifically, when children did not interpret an unaccented subject as the topic, it did not necessarily mean that they had no knowledge of the focus-to-accentuation mapping. They may have selected the picture containing the accented subject or the comment because the subject NP sounded more prominent and hence implied more importance. As pointed out by MacWhinney and Price (1980:9), 'there is no way of knowing in a given case whether a subject is pointing at what he takes to be the topic or at what he takes to be the comment'.

Taken together, in respect of production, there is only evidence for the ability to use emphatic accentuation to mark contrastive narrow focus by the age of 3 . This is not sufficient to conclude that children under age 6 can use accentuation to mark narrow focus in general. In respect of comprehension, there is no convincing evidence supporting the claim on children's inability to process the focus-to-accentuation mapping as attested in production at the age of 4 or 5 . These problems call into question the widely accepted claim that production precedes comprehension in the acquisition of the focus-to-accentuation mapping.

\section{The present study}

As a first step towards obtaining a clearer picture on the relation between production and comprehension in this aspect of intonational development, I will address the question of whether children can use accentuation to express non-contrastive narrow focus at the age of 4 or 5 by reanalysing data from recent production studies on children's and adults' use of intonation in marking non-contrastive topic and focus in SVO sentences in Dutch (Chen, accepted for publication, in preparation). ${ }^{1}$ Further, I will report a comprehension study on the processing of the non-contrastive narrow focus-toaccentuation mapping (hereafter the focus-to-accentuation mapping) in Dutch 4- to 5-year-olds and adults. In the production studies as well as the comprehension study, the focal constituent is an argument (subject or object) of the verb and realised with a full NP; focus is defined via a WH-question.

\subsection{Accentuation and narrow focus in production}

\subsubsection{Data elicitation}

Chen (accepted for publication, in preparation) investigated the intonation marking of narrow focus as well as topic in different positions in Dutch declarative sentences. SVO sentences were elicited as answers to WHAT- and WHO-questions from 4- to 5-year-old children as well as older children and adults by means of a picture matching game. In the game, the experimenter showed the participant a picture a time (e.g. a cleaning-lady with her hands up in front of her), gave a brief description of the picture (e.g. She seems to be picking up something), and then asked the participant a question about the picture (e.g. What is the cleaning-lady picking up?). The participant received the answer from a virtual robot via a headphone set (e.g. The cleaning-lady is picking up a vase.). The robot answered the question with abnormal prosody. ${ }^{2}$ The participant's task was to reconstruct the robot's answer in his/her own intonation. With the help of the participant's answer, the experimenter could find the matching picture (e.g. the picture of a vase). Thirty-six question-answer dialogues were embedded in the game. In half of the answer sentences, the sentence-initial NP (subject) was the focus and the sentence-final NP (object) the topic. In the other half of the answer sentences, the sentence-final NP was the focus and the sentence-initial NP the topic. Each noun was elicited in both the focus condition and the topic condition via different question-answer dialogues, as illustrated in (4).

(4)

A. Non-contrastive Narrow focus on the subject

Experimenter: Kijk! Een biet. Wie eet de biet?

"Look! A beet. Who is eating the beet?"

Participant: [Een poetsvrouw $]_{\text {focus }}$ eet [de biet $]_{\text {topic. }}$.

"A cleaning-lady is eating the beet."

\footnotetext{
${ }^{1}$ See Chen (2007) for initial results from adults.

2 The words that made up the robot's answer sentences were first recorded in a randomised wordlist by a female native speaker of Dutch. The words of each sentence were then spliced together with a $200 \mathrm{~ms}$ pause in between to form the sentence, similar to the method used by Müller et al. (2006). This way, no sentence-level intonational and rhythmical properties were present in the robots' sentences. In addition, the original pitch pattern of each sentence was erased and the pitch level was set at $200 \mathrm{~Hz}$ throughout the sentence such that the sentences sounded similar in pitch across trials. These measures proved to be very effective in getting children to talk in the question-answer dialogues as they normally did.
} 
Table 1

Summary of the results of the binary logistic regression analysis on the prediction that a noun was accented in adults' and children's production. The reference category of each predictor variable is given in brackets.

\begin{tabular}{|c|c|c|c|c|}
\hline & \multirow[t]{2}{*}{$B(\mathrm{SE})$} & \multicolumn{3}{|c|}{ 95\% Confidence interval for odds ratio } \\
\hline & & Lower & Odds ratio & Upper \\
\hline Constant & $0.36(0.18)$ & & & \\
\hline Focus status (focal) & $3.31^{* *}(0.43)$ & 11.80 & 27.25 & 62.93 \\
\hline Age (child) & $1.00^{* *}(0.25)$ & 1.65 & 2.72 & 4.47 \\
\hline Sentence position (initial) & $3.97^{* *}(0.54)$ & 18.38 & 52.70 & 151.10 \\
\hline Age $\times$ sentence position & $-2.50^{* *}(0.62)$ & 0.02 & 0.08 & 0.28 \\
\hline Age $\times$ focus status & $-1.58^{*}(0.55)$ & 0.07 & 0.21 & 0.61 \\
\hline
\end{tabular}

Note: $R^{2}=0.28$ (Hosmer and Lemeshow), 0.21 (Cox and Snell), 0.37 (Nagelkerke).

$p<0.0001$.

$p<0.005$.

B. Non-contrastive Narrow focus on the object

Experimenter: Kijk! Een poetsvrouw. Wat pakt de poetsvrouw?

"Look! A cleaning-lady. What is the cleaning-lady picking (up)?"

Participant: [De poetsvrouw $]_{\text {topic }}$ pakt [een vaas $]_{\text {focus. }}$.

"The cleaning-lady is picking (up) a vase."

\subsubsection{Intonation annotation}

In Chen (accepted for publication, in preparation), answer sentences from twelve 4- to 5-year-olds and nine adults were transcribed following the ToDI (Transcription of Dutch Intonation) notation (Gussenhoven, 2005) by means of the speech analysis software Praat (Boersma, 2001). The nouns affected by problems that could influence choice of intonation pattern, such as misplacement of word stress, disfluency, self-repair realised with emphatic accentuation, laughing while speaking, etc. were excluded from further analysis. In total, intonation patterns in 300 sentence-initial nouns and 276 sentence-final nouns produced by the 4- to 5-year-olds and intonation patterns in 291 sentence-initial nouns and 269 sentence-final nouns produced by the adults were subject to the statistical analysis, examining the effect of information structure (topic vs. focus) on choice of intonation pattern (i.e. various types of accent as well as lack of accentuation). For the present purpose, the intonation patterns in the selected nouns were recoded into two categories, accented and unaccented, by collapsing all accent types into one category 'accented'; the information structural conditions was recoded as focus and non-focus.

\subsubsection{Statistical analysis and results}

A binary logistic regression analysis with the forced entry method was conducted with accent placement as the dependent variable or the outcome variable (accented vs. unaccented) and focus status (focus vs. non-focus), sentence position (initial vs. final), and age group (child vs. adult) as the predictor variables. ${ }^{3}$ Both the main effects of the predictor variables and the interaction effects of three interactions involving two of the predictor variables and one interaction involving all the three predictor variables were specified as the covariates of the model. The model that was derived using all specified covariates as well as the constant predicted the outcome (i.e. a noun was accented) significantly better than the model derived using only the constant $\left(-2 \log\right.$-likelihood $\left.=689.92, \chi^{2}=271.09, \mathrm{df}=7, p<0.0001\right)$. The $b$-coefficients of the main effects and interaction effects showed that focus status, age group, sentence position, age group $\times$ sentence position, and age group $\times$ focal status made a significant contribution to the prediction of the outcome. The odds ratios (exp(B) values in the SPSS output) of these main effects and interaction effects are summarised in Table 1, in addition to the $b$-coefficients and their standard errors (SE).

The main effects of the three predictor variables were such that a noun was more likely to be accented when it was focal, when it was produced by a child, or when it occurred in sentence-initial position.

The effect of the interaction age group $\times$ sentence position was such that a sentence-initial noun was $92 \%(1-\exp (B))$ less likely to be accented when produced by a child than when produced by an adult, whereas a sentence-final noun was 3.57 times $(1 / \exp (B))$ more likely to be accented when produced by a child than when produced by an adult. This indicated that children accented sentence-initial nouns significantly less frequently than adults but accented sentence-final nouns significantly more frequently than adults, as shown in Fig. 1. The cross-tabulation of the distributions of accented nouns and unaccented nouns (Table 2) showed that the lower frequency of accented sentence-initial nouns in children held true for both the focus condition and the non-focus condition. In sentence-initial position, the noun was almost always accented in adults' production. The non-focal noun was accented however for rhythmic motivation, as argued in Chen (2007). Accenting the sentence-initial non-focal noun preceding the sentence-final focal noun leads to the preferred strong-weak (in the verb)-strong rhythmic pattern. Children strongly resembled adults in accenting sentence-initial nouns, though they accented slightly less frequently than adults (6\% less frequently in the focus condition and $8 \%$ less frequently in the non-focus condition). The higher frequency of accented sentence-final nouns in children held true for the non-focus condition only.

\footnotetext{
${ }^{3}$ The reference categories of the three predictor variables were non-focus, final position and adult respectively.
} 


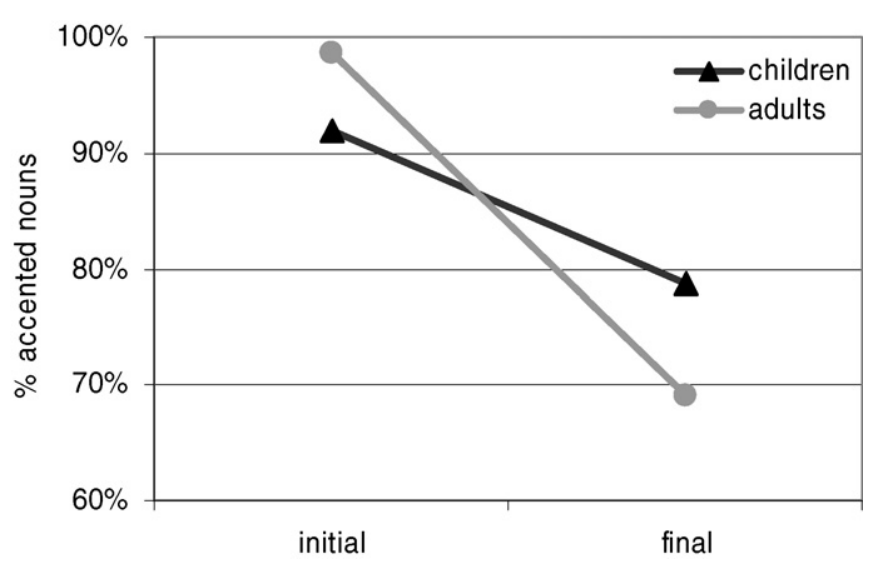

Fig. 1. Percentage of accented nouns in sentence-initial and sentence-final positions in adults' and children's production.

Table 2

Mean \% distributions of accent placement in adults and children.

\begin{tabular}{|c|c|c|c|c|c|}
\hline & & \multicolumn{2}{|l|}{ Adults } & \multicolumn{2}{|l|}{ Children } \\
\hline & & Accented & Unaccented & Accented & Unaccented \\
\hline \multirow[t]{2}{*}{ Sentence-initial } & Focus & $100 \%$ & 0 & $94 \%$ & $6 \%$ \\
\hline & Non-focus & $98 \%$ & $2 \%$ & $90 \%$ & $11 \%$ \\
\hline \multirow[t]{2}{*}{ Sentence-final } & Focus & $95 \%$ & $5 \%$ & $91 \%$ & $9 \%$ \\
\hline & Non-focus & $43 \%$ & $57 \%$ & $63 \%$ & $37 \%$ \\
\hline
\end{tabular}

More pertinent to the question as to whether children could use accentuation like adults in focus marking is the effect of the interaction age group $\times$ focus status. The odds ratio of this interaction showed that a focal noun was $39 \%$ less likely to be accented when produced by a child than when produced by an adult but the non-focal noun was 1.64 times more likely to be accented when produced by a child than when produced by an adult. This indicated that children accented a focal noun less frequently than adults but accented a non-focal noun more frequently than adults, as shown in Fig. 2. The lower frequency of accented focal nouns in children could be attributed to a less frequent use of accentuation in focal nouns in both sentenceinitial and sentence-final positions than in adults' production, although the difference was rather small (6\% in sentenceinitial focal nouns, $4 \%$ in sentence-final focal nouns), as can be seen in Table 2 . The higher frequency of accented non-focal nouns in children could be attributed to a more frequent use of accentuation in sentence-final non-focal nouns than in adults' production. The difference was substantial. Children accented sentence-final non-focal nouns in $63 \%$ of the cases, mainly using a rising accent $\left(\mathrm{L}^{*} \mathrm{H}\right)$ and a downstepped falling accent (i.e. a falling accent with a lowered peak in comparison to the preceding peak, transcribed as $! \mathrm{H}^{*} \mathrm{~L}$ ), whereas adults accented sentence-final non-focal nouns in $43 \%$ of the time, mostly with a downstepped falling accent. Chen (accepted for publication) suggested that the accent in sentence-final nouns may be placed for two reasons. One is for confirmation seeking, applicable to children's production in non-focal nouns as well as in



Fig. 2. Percentage of accented nouns in focal and non-focal conditions in adults' and children's production. 
focal nouns. In this case, a rising accent is used. The other reason is to introduce some free variation in the intonation, applicable to both adults' and children's production. In this case, a downstepped falling accent is used, possibly as an alternative to unaccenting in the non-focal nouns and to the falling accent in the focal-nouns.

\subsubsection{Discussion}

When considering the use of accentuation in the case of focal nouns alone, we see that children were rather similar to adults except for a small though statically significant difference in the frequency of accentuation. Children accented a focal noun in about $93 \%$ of the cases, whereas adults accented a focal noun in about $98 \%$ of the cases. However, when considering the use of the accentuation in the case of non-focal nouns, we see that children were rather different from adults in accenting a sentence-final non-focal noun far more frequently than adults, possibly for non-information structure related motivations. It is important to consider the use of accentuation in bother focal and non-focal nouns because if a child accents a word regardless of whether it is focal or not, an analysis on the focal nouns alone can lead to the wrong conclusion. The current results suggest that 4- to 5-year-olds can use accentuation to realise non-contrastive narrow focus but are not yet fully adultlike in the extent to which they use accentuation in the focal condition as well as in the non-focal condition, in particular in sentence-final position.

\subsection{Processing of focus-to-accentuation mapping}

\subsubsection{Method}

Psycholinguistic studies on adults' language comprehension have shown that generally, appropriate intonation facilitates comprehension and inappropriate intonation slows down comprehension (see Cutler et al., 1997 for a literature review). In particular, using the reaction time (RT) technique Birch and Clifton (1995) found that when adults were asked to judge whether the answer made sense in a question-answer dialogue (e.g. Isn't Kerry pretty smart? Yes, she teaches math.), they had shorter RTs and tended to make more YES judgements in answer sentences with appropriate focus-to-accentuation mapping than in answer sentences with inappropriate focus-to-accentuation mapping. The RT technique has been widely used in studies on sentence processing in 4-year-olds and older children (Clahsen, 2008). In the present study, Birch and Clifton's RT paradigm was adapted to investigate children's processing of the focus-to-accentuation mapping in questionanswer dialogues. Children and adults were presented with question-answer dialogues between two speakers and were asked to judge whether the answer was correct or incorrect in each dialogue. The 'make sense' task in Birch and Clifton's study was not used because the concept of 'make sense' was too abstract for 4- to 5-year-olds to comprehend. The experiment was presented to children as a game.

3.2.1.1. The game. The game was described to children as follows: "In the game, a boy is going to look at a number of pictures with his three pets, a parrot, a chicken, and a duck. He wants to know whether his pets know the pictures well and which of the pets knows the pictures best. To find this out, he will show a picture a time to one of his pets and ask the pet a question about the picture. You will listen to the dialogues between the boy and his pets via a headphone set and get to see each picture on a computer screen together with the boy and his pets. What you need to do is to judge whether the pets have given correct answers to the boy's questions or not. If you think that a pet gave a correct answer, press the green button of the pushbutton box. If you think that the pet's answer is incorrect for some reason, press the red button.'

3.2.1.2. Experimental design and predictions. Two factors were varied in the experimental stimuli, i.e. accent placement in the answer sentence (2 levels: pragmatically appropriate accent placement vs. pragmatically inappropriate accent placement), focus location (2 levels: the object NP vs. the subject NP). The variable 'focus location' was defined by the questions. WHOquestions put the subject NP in the answer sentence in focus; WHAT-questions put the object NP in the answer sentence in focus. Combining the two independent variables led to four experimental conditions: pragmatically appropriate accent placement-object focus, pragmatically appropriate accent placement-subject focus, pragmatically inappropriate accent placement-object focus, and pragmatically inappropriate accent placement-subject focus. Each experimental condition was implemented on six experimental dialogues. The answers in the experimental dialogues were lexically and semantically correct answers. It was assumed that if an answer was judged to be incorrect, it could only be due to the accent placement.

To add variation to the stimuli, two types of fillers were constructed, in which the answer sentences were incorrect either because of a lexico-semantic error or a pronunciation error. Each experimental condition was implemented on three fillers with a lexico-semantic error and two fillers with a pronunciation error.

In total, every participant was presented with 44 dialogues $(4$ experimental conditions $\times 6$ experiment dialogues +4 experimental conditions $\times 3$ fillers with a lexico-semantic error +4 experimental conditions $\times 2$ fillers with a pronunciation error). Two measures were taken, i.e. the 'correct-incorrect' judgement and the RT.

If participants can process the focus-to-accentuation mapping, this should show up in their RTs and possibly also in their 'correct-incorrect' judgements. In line with Birch and Clifton's findings (1995), we expected participants to respond faster and make more 'correct-answer' judgements in answer sentences with pragmatically appropriate accent placement than in answer sentences with pragmatically inappropriate accent placement, regardless of focus location. If children under the age of 6 cannot process the focus-to-accentuation mapping as claimed in the literature, we would observe no effect of accent placement on the 'correct-incorrect' judgements and the RTs. 
Table 3

Distribution of accent patterns in subject and object nouns across conditions in the stimuli of the RT experiment.

\begin{tabular}{|c|c|c|c|c|c|c|c|}
\hline & & \multicolumn{3}{|c|}{ Subject noun } & \multicolumn{3}{|c|}{ Object noun } \\
\hline & & $\mathrm{H}^{*}$ & $\mathrm{H}^{*} \mathrm{~L}$ & No accent & $! \mathrm{H}^{*} \mathrm{~L}$ & $\mathrm{H}^{*} \mathrm{~L}$ & No accent \\
\hline Object-focus & Appropriate accent placement & 1 & 22 & 1 & 16 & 8 & 0 \\
\hline Subject-focus ${ }^{a}$ & Inappropriate accent placement & 2 & 22 & 0 & 21 & 3 & 0 \\
\hline Subject-focus & Appropriate accent placement & 0 & 24 & 0 & 9 & 0 & 15 \\
\hline Object-focus $^{\mathrm{b}}$ & Inappropriate accent placement & 1 & 23 & 0 & 2 & 0 & 22 \\
\hline
\end{tabular}

a This condition was elicited as object-focus.

b This condition was elicited as subject-focus.

3.2.1.3. Materials. Forty-four pairs of SVO sentences were constructed together with the accompanying colour pictures. All words in these sentences have been shown in the pilot tests to be known to 4- and 5-year-olds. The two sentences in a pair differed only in the article preceding the subject noun and the object noun. One sentence served as an answer with focus on the subject, in which the subject noun was preceded by an indefinite article and the object noun by a definite article; the other sentence served as an answer with focus on the object, in which the object noun was preceded by an indefinite article and the subject noun by a definite article. ${ }^{4}$

For each pair of answer sentences, corresponding question pairs were constructed. The question was preceded by an attention getter Kijk 'look' and the naming of the entity about which new information was required. The pair of answer sentences and the corresponding pair of questions together formed two pairs of question-answer dialogues, as shown in (5). The forty-four pairs of questions and answer sentences then led to 44 pairs of dialogues.

\author{
Kijk! Een kip! Wat eet de kip? \\ 'Look! A chicken! What is the chicken eating?' \\ De kip eet een plant. \\ 'The chicken is eating a plant.'
}

Kijk! Een plant! Wie eet de plant?

Look! A plant! Who is eating the plant?

Een kip eet de plant.

A chicken is eating the plant.

Among the 44 pairs of dialogues, 24 pairs served as the experimental dialogues. The other 20 pairs served as the fillers (12 as fillers with a lexico-semantic error and 8 as fillers with a pronunciation error). In the answer sentences of fillers with a lexico-semantic error, the focal noun was replaced with a noun conveying wrong information (e.g. 'duck' instead of 'chicken'). In the answer sentences of fillers with a pronunciation error, the focal noun was replaced with a version of the noun with the stressed vowel wrong (e.g. jaangen instead of jongen 'boy').

The questions of the dialogues were recorded by a male speaker of Dutch at $44.1 \mathrm{kHz}$ sampling frequency with 16 bits resolution in the recording studio of the Max Planck Institute for Psycholinguistics (MPI) in Nijmegen. Because of the similarities between child-direct speech and pet-directed speech in pitch characteristics (Burnham et al., 2002), the male speaker was instructed to read the questions and the preceding utterances as if he was talking to a child. The answer sentences of the dialogues were recorded by a female native speaker of Dutch together with the male speaker, who read the questions only. The female speaker was instructed to read the answers normally. To obtain readings of the answer sentences with pragmatically inappropriate accent placement, additional questions were derived from the original questions by changing the article from definite to indefinite. The derived WHAT-questions were combined with the answer sentences to the original WHO-questions to elicit readings of these answer sentences with inappropriate accent placement in the context of WHO-questions. The same was done to elicit readings of the answer sentences with inappropriate accent placement in the context of WHAT-questions.

To establish the intonational consistency in the answer sentences of the experimental dialogues, these sentences were annotated for accent patterns following the ToDI notation and for phonetic details, including the begin and end of the sentence, the highest pitch, and the lowest pitch following the highest pitch in the nouns. In respect of accent patterns, three types of accents occurred in the answer sentences, $\mathrm{H}^{*} \mathrm{~L}$ (a falling accent), $\mathrm{H}^{*}$ (a sustained high level accent or a rising accent with no recognisable low tone preceding the rise), and $! \mathrm{H}^{*} \mathrm{~L}$. As can be seen in Table 3 , the speaker consistently accented subject noun with $\mathrm{H}^{*} \mathrm{~L}$ and the object noun with $! \mathrm{H}^{*} \mathrm{~L}$ and $\mathrm{H}^{*} \mathrm{~L}$ in sentences elicited with object focus (i.e. sentences in the object focus-appropriate accent placement condition and sentences in the subject focus-inappropriate accent placement

\footnotetext{
${ }^{4}$ The use of articles in the answer sentences followed the pattern of new-definite article and given-indefinite article. This was to ensure that the choice of article was pragmatically appropriate and would not be the cause for a faster or slower response. This way, we could reliably attribute changes in reaction times to the two independent variables, accent placement and focus location.
} 


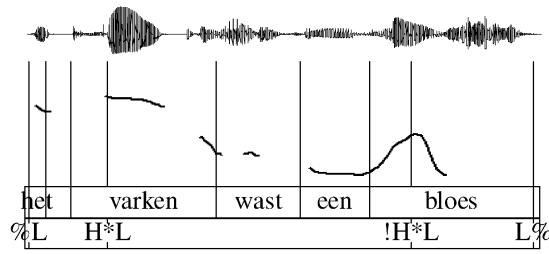

object focus-appropriate accent placement

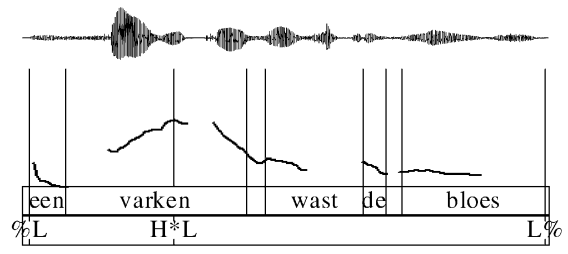

subject focus-appropriate accent placement

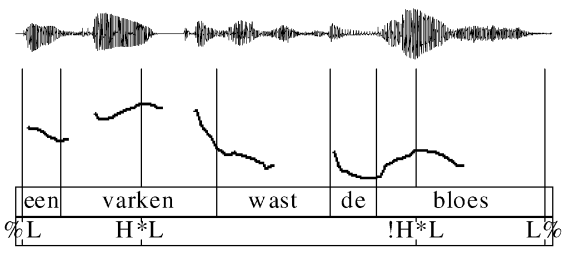

subject focus-inappropriate accent placement

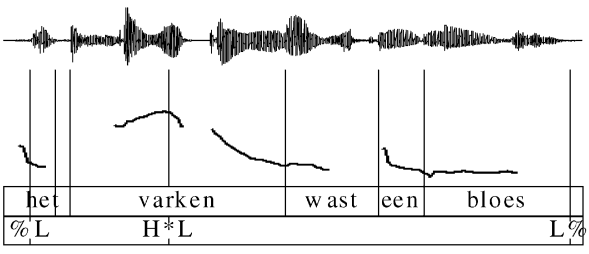

object focus-inappropriate accent placement

Fig. 3. Representative contours in the four experimental conditions realised in Het/een varken wast een/de bloes 'The/a pig is washing a/the blouse'.

condition), and accented the subject noun with $\mathrm{H}^{*} \mathrm{~L}$ and pronounced the object noun mostly with no accent and occasionally with ! $\mathrm{H}^{*} \mathrm{~L}$ in sentences elicited with subject focus (i.e. sentences in the subject focus-appropriate accent placement condition and sentences in the object focus-inappropriate accent placement condition). The representative pattern in each condition is illustrated in Fig. 3. In respect of the phonetic details, sentence duration, peak height, and pitch range of the fall following the pitch peak were automatically extracted in Praat on the basis of the phonetic annotation. In about one-third of the sentences elicited with object focus, the difference in peak height between $! \mathrm{H}^{*} \mathrm{~L}$ and the high tone in the subject noun was much bigger than that in the rest of the sentences. To minimise possible effects of such variation on processing, local pitch manipulation was conducted to lower the peak in the subject noun and/or to raise the peak of ! $\mathrm{H}^{*} \mathrm{~L}$ so that the difference between the peaks in these sentences was similar to the rest of the sentences. Table 4 shows the mean peak height in the subject nouns, the mean peak height and mean pitch range of the fall in $! \mathrm{H}^{*} \mathrm{~L}$ and $\mathrm{H}^{*} \mathrm{~L}$ in the object nouns in semitones (with $1 \mathrm{~Hz}$ as the reference value), and the mean duration of the sentences across conditions after the local pitch manipulation in part of the sentences. As can be seen, the sentences elicited with the same focus location were also comparable in these phonetic parameters.

A Latin square was used to distribute the experimental dialogues and fillers over the experimental conditions. Four lists were created such that every dialogue and filler appeared in every experimental condition but not in the same list. Two pseudo-randomised orders were created for each list, resulting in eight stimulus orders.

3.2.1.4. Participants. Twenty 4- to 5-year-old children (4;3-5;7, mean age: $5 ; 1)$ from Adalbert Primary School in Mook and fifteen students (controls) at Radboud University Nijmegen participated in the experiment. All participants were monolingual native speakers of Dutch and reported to have normal hearing and speaking. All but one child were righthanded.

3.2.1.5. Procedure. Children were tested individually in a quiet room at their school. Adults were tested individually in an experiment room at the MPI. The experiment was conducted by means of NESU (Nijmegen Experiment Setup) experiment software. Participants were randomly assigned to a stimulus order but a new participant was assigned to a stimulus order only when an equal number of participants had already been assigned to all the eight stimulus orders. Each test session

\section{Table 4}

Mean peak height and mean pitch range in semitones (st) in subject and object nouns and mean duration of sentences in milliseconds (ms) across conditions in the stimuli of the RT experiment.

\begin{tabular}{|c|c|c|c|c|c|c|c|c|c|}
\hline & & \multirow{2}{*}{\multicolumn{3}{|c|}{$\begin{array}{l}\text { Subject noun } \\
\text { Peak height (st) }\end{array}$}} & \multicolumn{4}{|c|}{ Object noun } & \multirow{3}{*}{$\begin{array}{l}\text { Duration of } \\
\text { sentence (ms) }\end{array}$} \\
\hline & & & & & \multicolumn{2}{|c|}{$\begin{array}{l}\text { Peak } \\
\text { height (st) }\end{array}$} & \multicolumn{2}{|c|}{$\begin{array}{l}\text { Range } \\
\text { of fall (st) }\end{array}$} & \\
\hline & & All & $\begin{array}{l}\text { With } \mathrm{H}^{*} \mathrm{~L} \\
\text { in object }\end{array}$ & $\begin{array}{l}\text { With ! } \mathrm{H}^{*} \mathrm{~L} \\
\text { in object }\end{array}$ & $\mathrm{H}^{*} \mathrm{~L}$ & $! \mathrm{H}^{*} \mathrm{~L}$ & $\overline{\mathrm{H}^{*} \mathrm{~L}}$ & $\overline{! \mathrm{H}^{*} \mathrm{~L}}$ & \\
\hline Object-focus & Appropriate accent placement & 101 & 100 & 101 & 100 & 98 & 9 & 6 & 1222 \\
\hline Subject-focus & Inappropriate accent placement & 99 & 99 & 99 & 96 & 95 & 6 & 5 & 1244 \\
\hline Subject-focus & Appropriate accent placement & 101 & & 102 & & 94 & & 4 & 1462 \\
\hline Object-focus & Inappropriate accent placement & 98 & & 98 & & 91 & & 2 & 1408 \\
\hline
\end{tabular}


lasted about 20 min with children and about 15 min with adults, starting with a practice session. In the practice session, participants were familiarised with the task and trained to use both hands to hold the push-button box with the thumbs resting on the buttons so that they could press the buttons as quickly as possible.

The timeline of a trial was as follows: A target picture together with the picture of the boy and one of his pets appeared on the screen. At the same time, the boy said 'Kijk'. 800 ms later, he named an entity in the picture. The 800 -ms delay was built in to allow participants to take a proper look at the picture. $1200 \mathrm{~ms}$ after the naming, the boy asked the question. $2200 \mathrm{~ms}$ after the end of the question, the pet answered the question. To make the task somewhat harder for the adults, the answer was played $700 \mathrm{~ms}$ after the end of the question instead of $2200 \mathrm{~ms}$. At the end of the answer sentence, a timer with $1 \mathrm{~ms}$ accuracy was activated and a picture of the push-button box appeared on the screen. The RT was recorded from the end of each answer sentence until a button was pressed and the correct-incorrect judgment was automatically recorded in NESU.

Participants were instructed to press the button as quickly as they could, but not before the end of the answer sentence. A timeout device was set at $4 \mathrm{~s}$ after the end of sentence in the tests with children and at $2 \mathrm{~s}$ after the end of sentence in the tests with adults. If no response was given before timeout, a clock appeared on the computer screen and next trial was initiated.

\subsubsection{Results and discussion}

The data of three adults were not included in statistical analysis for the sake of a balanced distribution of number of participants per stimulus list. The data of eight children were discarded because one child did not complete the experiment, one child appeared to have poorly understood the experimental task and often pressed a button before hearing the answers, and six children either hold the push-button box with one hand or left the box on the desk with their hands resting on their knees and used one finger to press the buttons. This left us usable data from 12 adults ( 3 per stimulus list) and 12 children ( 3 per stimulus list).

3.2.2.1. Correct-incorrect judgements. Adults judged the answers in the experimental dialogues, which were lexically and semantically correct, frequently to be correct (94\%), but the answers in the fillers, containing lexico-semantic or pronunciation errors, frequently to be incorrect (95\% in fillers with a lexico-semantic error, $94 \%$ in fillers with a pronunciation error). Similarly, children judged the answers in the experimental dialogues mostly to be correct (73\%) but the answers in the fillers mostly to be incorrect (72\% in fillers with a lexico-semantic error and $61 \%$ in fillers with a pronunciation error), though they made fewer 'correct' judgments in the experimental dialogues and 'incorrect' judgements in the fillers than adults.

To find out the effect of intonation, focus location and age group on the correct-incorrect judgements in the experimental stimuli, a binary logistic regression analysis was conducted with the correct-incorrect judgements as the dependent variable or the outcome variable and accent placement (pragmatically appropriate vs. pragmatically inappropriate), focus location (subject NP vs. object NP), and age group (child vs. adult) as the predictor variables. Both the main effects of the predictor variables and the interaction effects of three interactions involving two of the predictor variables and one interaction involving all the three predictor variables were specified as the covariates of the model. All but twelve timeouts (responses made after timeout) were entered into the model. The model derived using all specified covariates as well as the constant predicted the outcome (i.e. an answer was correct) significantly better than a model derived using only the constant ( -2 loglikelihood $\left.=435.57, \chi^{2}=68.34, \mathrm{df}=7, p<0.0001\right)$. However, only the predictor variable age group made a significant contribution to the prediction of the outcome. The odds ratio (Table 5) showed that an answer was $91 \%$ less likely to be considered as a correct answer when the judge was a child than when the judge was an adult. This is in line with the difference in the percent distribution of correct-answer judgements between adults and children observed above. Our interview with children shortly after the experiment revealed that they rejected the answers in the experimental dialogues as correct answers because of different interpretations of the objects in the pictures (e.g. 'grass' instead of 'plant', 'Father Christmas' instead of 'dwarf, 'Papa' instead of 'man', etc.) or false perception of pronunciation errors.

Note that in Birch and Clifton's study, pragmatically appropriate accent placement triggered more 'make sense' judgements than inappropriate accent placement in adults. Possibly, when asked to judge the sensibility of an answer to a question in out-of-the-blue question-answer dialogues, listeners considered not only the lexical-semantic content of the answer but also how the answer was said. But when asked to judge whether a speaker has given a correct answer to a question about a picture and the answer was visible in the picture, listeners have focused on the lexical-semantic content of the answer and compared the content of the answer to what they perceived in the picture. As a result, intonation played little role in judgements on whether an answer was correct or not.

\section{Table 5}

Summary of the results of the binary logistic regression analysis on the prediction that an answer was correct in adults' and children's judgements. The reference category of the predictor variable is given in brackets.

\begin{tabular}{llll}
\hline & $B(\mathrm{SE})$ & 95\% Confidence interval for odds ratio & Odds ratio \\
\cline { 3 - 4 } & & Lower & Upper \\
\hline Constant & $3.56(0.72)$ & 0.02 & 0.09 \\
Age group (child) & $-2.38^{*}(0.77)$ & 0.42 \\
\hline
\end{tabular}

Note: $R^{2}=0.14$ (Hosmer and Lemeshow), 0.12 (Cox and Snell), 0.19 (Nagelkerke).

$p<0.005$. 


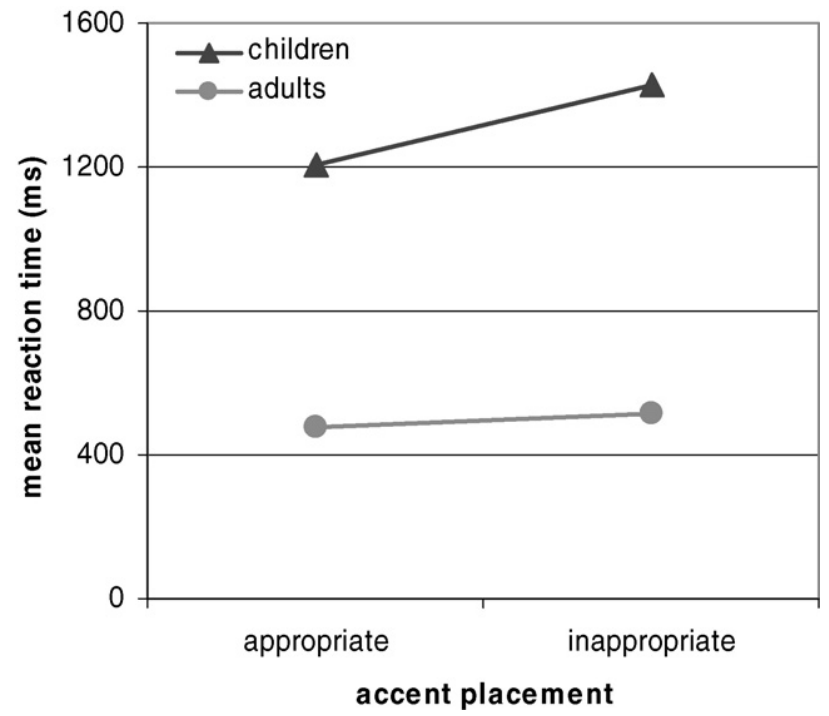

Fig. 4. Mean reaction times (ms) in adults and children in appropriate and inappropriate accent placement conditions

3.2.2.2. Reaction time. A repeated measures ANOVA was conducted on the RTs to assess the effect of accent placement, focus location and age group (between-subject factor) on how fast the participants made a judgement. Twelve timeouts and 27 RTs greater than 4 standard deviations (SD) above a participant's mean RT in the experimental trials were replaced with the mean RT obtained from the other trials in the relevant condition of the participant. The mean RT of each condition was then computed for each participant and subject to the repeated measures ANOVA at the significance level of 0.05 . The measure of effect size used here was partial eta squared $\left(\eta_{p}^{2}\right)$.

The ANOVA revealed a main effect of focus location $\left(F(1,22)=17.03, p<0.001, \eta_{p}^{2}=0.44\right)$, a main effect of accent placement $\left(F(1,22)=16.60, p<0.005, \eta_{p}^{2}=0.43\right)$, a main effect of age group $\left(F(1,22)=69.12, p<0.0001, \eta_{p}^{2}=0.76\right)$, and a significant interaction of accent placement $\times$ age group $\left(F(1,22)=9.08, p<0.01, \eta_{p}^{2}=0.29\right)$. The main effect of focus location is such that object focus triggered a longer mean RT than subject focus (1016 ms vs. 883 ms). This may be explained by the fact that in sentences with object-focus listeners had to wait till the end of the sentence to hear the focal word and therefore were slower in forming a judgment on whether the answer was correct or not, whereas in sentences with subjectfocus they heard the focal word early in the sentence and could form their judgement before the end of the sentence. The main effect of age group is such that children were significantly slower than adults (1404 ms vs. $496 \mathrm{~ms}$ ), as commonly found in earlier work on language processing using the RT technique. Regarding the main effect of accent placement, appropriate accent placement triggered a shorter mean RT than inappropriate accent placement ( $873 \mathrm{~ms} v$. $1027 \mathrm{~ms}$ ). The effect of the interaction between accent placement and age group is such that although appropriate accent placement triggered a shorter mean RT than inappropriate accent placement in both adults and children, the difference in RT between the two accent placement conditions was bigger for children (1209 ms vs. $1429 \mathrm{~ms}$ ) than for adults (479 ms vs. $512 \mathrm{~ms}$ ), as illustrated in Fig. 4. Considering the substantial difference in RTs between adults and children, the effect of the interaction between accent placement and age group could be caused by the difference in the absolute reaction times between adults and children. The ratio between the RT in each condition and the mean RT averaged over all conditions was subsequently computed for each participant to normalise the difference in the absolute RTs between adults and children, and subject to the repeated measures ANOVA on the ratios. No significant interaction between accent placement and age group was found. ${ }^{5}$

To sum up, the results have shown that even though accent placement played no role in correct-incorrect judgements, it did affect how fast participants made a judgement. Both adults and 4- to 5-year-olds were faster in deciding whether an answer was correct in the appropriate accent placement condition than in the inappropriate accent placement condition. This finding indicates that like adults, 4- to 5-year-olds can process the focus-to-accentuation mapping, contra earlier claims in the literature.

\section{Conclusion and future research}

Past work has shown that children can use accentuation to mark contrastive narrow focus in simple declarative sentences by age 3 and do this more frequently as they grow older. But little is known when children become adult-like in the degree to which they accent contrastive narrow focus. The reanalysis of data from Chen (accepted for publication, in preparation) has

\footnotetext{
${ }^{5}$ Another difference in the results between the two ANOVA's was that the interaction between focus location and age group reached significance in the ANOVA on RT ratios. The difference in RT ratio between the subject-focus condition and the object-focus condition was bigger in adults than in children.
} 
provided evidence that children can also use accentuation to mark non-contrastive narrow focus in SVO sentences at the age of 4 or 5, like adults, although they accent the focal noun slightly less frequently than adults and tend to accent the non-focal noun in sentence-final position to seek confirmation.

In respect of children's comprehension of accentuation as a cue to focus, the majority of the earlier work cited in support of children's inability to process the focus-to-accentuation mapping in the literature has examined uses of accentuation that are related to but go beyond the focus-to-accentuation mapping, e.g. the use of accentuation to disambiguate pronouns, accentuation as a cue to contrastive focus in sentences with the focus particle 'only'. The comprehension of these uses of accentuation requires additional knowledge of the semantics of the sentence and logical thinking in addition to knowledge of the focus-to-accentuation mapping. Children's failure to comprehend accentuation in these cases therefore does not necessarily suggest a lack of knowledge of the focus-to-accentuation mapping. Different from previous studies, using the RT technique I investigated the processing of the (non-contrastive narrow) focus-to-accentuation mapping in discourse contexts in which children from the same age group can use accentuation to mark non-contrastive narrow focus, namely, question-answer dialogues. It was found that correct mapping between accentuation and focus triggered shorter RTs than incorrect mapping in SVO answer sentences in 4- to 5-year-olds as well as in adults when asked to judge whether the answers were correct, although children were overall slower than adults. This result shows that 4- to 5-year-olds can process the focus-to-accentuation mapping in online language comprehension, contra past claims.

The current production and comprehension results thus provide no evidence for the alleged asymmetry between production and comprehension. Rather, the results suggest that children's comprehension is similar to their production at the age of 4 or 5 in. That is, children exhibit similar patterns to adults in both production and comprehension but are not yet fully adult-like. However, the difference between adults and children is mainly of a gradient nature.

The present study has taken our understanding of the relation between production and comprehension of the focus-toaccentuation mapping a step forward. Much work still remains to be done in this line of research. First of all, this study is concerned with the focus-to-accentuation mapping in the arguments of the verb. The picture may be different when it comes to other constituents. For example, Baltaxe (1984) found that 3-year-olds failed to accent the verb in SVO sentences when it was the contrastive focus whereas their use of emphatic accentuation was flawless in the subject and object positions. Hornby and Hass (1970) reported that 4- to 5-year-olds used emphatic accentuation less frequently to mark contrast between verbs than between subjects in SVO sentences. The research on the acquisition of the focus-to-accentuation mapping should be extended from the arguments of the verb to the verb in SVO and SV sentences and other constituents in more complex sentences.

Furthermore, the focus under investigation has a narrow scope. As mentioned in section 1, focus can have a scope broader than the accented noun. In this case, the speaker needs to know where the accent should go. For example, when the VP of SVO sentences is in focus, native speakers of English prefer to accent the object noun only; this accent then projects focus to the verb (Gussenhoven, 1983; Ladd, 1996). The same holds true for Dutch and German. No study to date has investigated children's production and comprehension of the focus-to-accentuation mapping in cases of broad focus. This would be a very useful direction for future study towards gaining more insights into the relation between production and comprehension of accentuation as a cue to focus.

Finally, intonational marking of focus is more than accent placement. The choice of accent type also plays an important role. For example, in Dutch the preferred accent type to mark focus is $\mathrm{H}^{*} \mathrm{~L}$ in both contrastive and non-contrastive focus. Chen (accepted for publication) has found that children showed no preference for $\mathrm{H}^{*} \mathrm{~L}$ over $! \mathrm{H}^{*} \mathrm{~L}, \mathrm{H}^{*}$ and $\mathrm{L}^{*} \mathrm{H}$ in sentence-final focus at the age of 4 or 5 and that they became adult-like in choice of accent type only at the age of 7 or 8 . Much research remains to be done to find out how accent type affects the processing of the focus-to-accentuation mapping in children from different age groups.

\section{Acknowledgements}

I thank Hanna Birmans and Tilman Harp for drawing the pictures, Rik van den Brule and Annemarie Frye for recording the material and testing the participants. I am also grateful to Christine Dimroth, Juhani Järvikivi, Wolfgang Klein, and Leah Roberts for their useful feedback and John Nagengast for his timely help with NESU. Special thanks go to the children, their parents, and Adalbert Primary School in Mook for their cooperation.

\section{References}

Allen, S., Skarabela, B., Hughes, M., 2008. Using corpora to examine discourse effects in syntax. In: Behrens, H. (Ed.), Corpora in Language Acquisition Research: Finding Structure in Data. Benjamins, Amsterdam, pp. 99-138.

Baltaxe, C., 1984. Use of contrastive stress in normal, aphasic, and autistic children. Journal of Speech and Hearing Research $27,97-105$.

Bates, E., 1976. Language in Context. Academic Press, New York.

Baumann, S., Becker, J., Grice, M., Mücke, D., 2007. Tonal and articulatory marking of focus in German. In: Trouvain, J., William, J.B. (Eds.), Proceedings of the 16th International Congress of Phonetic Sciences. Pirrot GmbH, Dudweiler, pp. 1029-1032.

Behrens, H., Gut, U., 2005. The relationship between prosodic and syntactic organization in early multiword speech. Journal of Child Language $32,1-34$. Bergsma, W., 2002. Children's interpretations of Dutch sentences with the focus particle Alleen ('Only'). In: Lasser, I. (Ed.), Proceedings of the GALA (Generative Approaches to Language Acquisition) 1999, Peter Lang, Frankfurt (Main).

Birch, S., Clifton, C.J., 1995. Focus, accent, and argument structure: effects on language comprehension. Language and Speech 38 (4), $365-391$.

Boersma, P., 2001. Praat, a system for doing phonetics by computer. Glot International 5 (9/10), 341-345.

Brown, R., 1973. A First Language. Harvard University Press, Cambridge. 
Burnham, D., Kitamura, C., Vollmer-Conna, U., 2002. What's new, Pussycat? On talking to babies and animals. Science 296 (5572), 1435.

Chafe, W.C., 1974. Language and consciousness. Language 50 (1), 111-133.

Chafe, W.C., 1976. Givenness, contrastiveness, definiteness, subjects, topics, and point of view. In: Li, C. (Ed.), Subject and Topic. Academic Press, New York, pp. 25-55.

Chen, A. Intonational Realisation of Topic and Focus in Dutch Declaratives, in preparation.

Chen, A. Tuning information structure: intonational realisation of topic and focus in child Dutch. Journal of Child Language, accepted for publication.

Chen, A., 2007. Intonational realisation of topic and focus by Dutch-acquiring 4- to 5-year-olds. In: Trouvain, J., William, J.B. (Eds.), Proceedings of the 16th International Congress of Phonetic Sciences. Pirrot GmbH, Dudweiler, pp. 1553-1556.

Chen, A., Fikkert, P., 2007a. Intonation of early two-word utterances in Dutch. In: Trouvain, J., William, J.B. (Eds.), Proceedings of the 16th International Congress of Phonetic Sciences. Pirrot GmbH, Dudweiler, pp. 315-320.

Chen, A., Fikkert, P., 2007b. Dutch 3-year-olds' use of intonation in marking topic and focus. In: Poster Presented at GALA 2007, Barcelona.

Chien, Y.C., Wexler, K., 1991. Children's knowledge of locality conditions in binding as evidence for the modularity of syntax and pragmatics. Language Acquisition 1 (3), 225-295.

Clahsen, H., 2008. Behavioral methods for investigating morphological and syntactic processing in children. In: Sekerina, I.A., Fernández, E.M., Clahsen, H. (Eds.), Developmental Psycholinguistics: On-line Methods in Children's Language Processing. John Benjamins, Amsterdam, pp. 1-28.

Crain, S., Ni, W., Conway, L., 1994. Learning, parsing and modularity. In: Clifton, C., Frazier, L., Rayner, K. (Eds.), Perspectives on Sentence Processing. Lawrence Erlbaum, Hillsdale, NJ, pp. 443-467.

Cruttenden, A., 1985. Intonation comprehension in ten-year-olds. Journal of Child Language 12, 643-661.

Cutler, A., Swinney, D.A., 1987. Prosody and the development of comprehension. Journal of Child Language 14, $145-167$.

Cutler, A., Dahan, D., van Donselaar, W., 1997. Prosody in the comprehension of spoken language: a literature review. Language and Speech 40 (2), $141-201$.

De Cat, C., 2008. Experimental evidence for preschoolers' mastery of “topic”. In: Gavarró, A., Freitas, M.J. (Eds.), Proceedings of GALA 2007. Cambridge Scholars Publishing, Cambridge, pp. 155-165.

Drodz, K.F., van Loosbroek, E., 1998. Dutch children's interpretation of focus particle constructions. In: Poster Presented at the 23rd Annual Boston University Conference on Language Development, Boston, MA.

Gualmini, A., Maciukaite, S., Crain, S., 2002. Children's insensitivity to contrastive stress in sentences with ONLY. Penn Working Papers in Linguistics 9 (1).

Gussenhoven, C., 1983. Testing the reality of focus domains. Language and Speech 26 (1), 61-80.

Gussenhoven, C., 2005. Transcription of Dutch intonation. In: Jun, S. (Ed.), Prosodic Typology and Transcription: A Unified Approach. Oxford University Press, Oxford, pp. 118-145.

Gussenhoven, C., 2006. Types of focus in English. In: Lee, C., Gordon, M., Büring, D. (Eds.), Topic and Focus: Cross-linguistic Perspectives on Meaning and Intonation. Kluwer, Dordrecht, pp. 83-100.

Halliday, M.A.K., 1967. Notes on transitivity and theme in English (II). Journal of Linguistics 3, 199-244.

Hanssen, J., Peters, J., Gussenhoven, C., 2008. Prosodic effects of focus in Dutch declaratives. In: Barbosa, P.A., Madureira, S., Reis, C. (Eds.), Proceedings of the 4th International Conferences on Speech Prosody, Editora RG/CNPq, Campinas, pp. 609-612.

Hendriks, P., 2005. Asymmetries in the acquisition of contrastive stress. In: Paper presented at the workshop on Contrast, Information Structure and Intonation. Stockholm University, October 28-29, 2005 Retrieved from http://www.let.rug.nl/ hendriks on 21 June 2006.

Hickmann, M., Roland, F., 1990. Topics and subjects in narratives of French children. In: Paper presented at the 3rd Conference of the Réseau Européen de Laboratoires sur l'Acquisition des Langues.

Hornby, P.A., 1971. Surface structure and the topic-comment distinction: a developmental study. Child Development 42, 1975-1988.

Hornby, P.A., Hass, W.A., 1970. Use of contrastive stress by preschool children. Journal of Speech and Hearing Research $13,359-399$.

Ladd, D.R., 1980. The Structure of Intonational Meaning: Evidence from English. Indiana University Press, Bloomington.

Ladd, D.R., 1996. Intonational Phonology. Cambridge University Press, Cambridge.

Lahey, M., 1974. Use of prosody and syntactic markers in children's comprehension of spoken sentences. Journal of Speech and Hearing Research 17, 656668.

Lambrecht, K., 1994. Information Structure and Sentence Form: Topics, Focus, and the Representations of Discourse Referents. Cambridge University Press, Cambridge.

MacWhinney, B., Bates, E., 1978. Sentential devices for conveying givenness and newness: a cross-cultural developmental study. Journal of Verbal Learning and Verbal Behavior 17, 539-558.

MacWhinney, B., Price, D., 1980. The development of the comprehension of topic-comment marking. In: Ingram, D., Peng, C.C., Dale, P. (Eds.), Proceedings of the 1st International Congress for the Study of Child Language. University Press of America, Lanham, MD.

McDaniel, D., Maxfield, T., 1992. Principle B and contrastive stress. Language Acquisition 2, 337-358.

Müller, A., Höhle, B., Schmitz, M., Weissenborn, J., 2006. Focus-to-stress Alignment in 4- to 5-year-old German-learning Children. In: Belletti, A., Bennati, E., Chesi, C., Di Domenico, E., Ferrari, I. (Eds.), Proceedings of GALA 2005. Cambridge Scholars Publishing, Cambridge, pp. $393-407$.

Paterson, K.B., Liversedge, S.P., White, D., Filik, R., Jaz, K., 2006. Children's interpretation of ambiguous focus in sentences with “Only”. Language Acquisition $13(3), 253-284$.

Reinhart, T., 1999. The processing cost of reference-set computation: guess patterns in acquisition. In: OTS Working Papers in Linguistics.

Rooth, M.E., 1992. A theory of focus interpretation. Natural Language Semantics 1, 75-116.

Solan, L., 1980. Contrastive stress and children's interpretation of pronouns. Journal of Speech and Hearing Research 23, 688-698.

Szendröi, K., 2004. Acquisition evidence for an interface theory of focus. In: van Kampen, J., Baauw, S. (Eds.), Proceedings of GALA 2003.

Vallduví, E., Engdahl, E., 1996. The linguistic realisation of information packaging. Linguistics 34, 459-519.

Wells, B., Local, J., 1993. The sense of an ending: a case of prosodic delay. Clinical Linguistics and Phonetics 7 (1), $59-73$.

Wells, B., Peppé, S., Goulandris, N., 2004. Intonation development from five to thirteen. Journal of Child Language 31 (4), $749-778$.

Weir, R.H., 1962. Language in the Crib. Mouton, The Hague.

Wiemann, L.A., 1976. Stress patterns in early child language. Journal of Child Language 3, 283-286. 